\title{
Wolfram syndrome 1 and adenylyl cyclase 8 interact at the plasma membrane to regulate insulin production and secretion
}

\author{
Sonya G. Fonseca ${ }^{1,4}$, Fumihiko Urano ${ }^{2}$, Gordon C. Weir ${ }^{3}$, Jesper Gromada ${ }^{1}$, and Mark \\ Burcin $^{1}$ \\ ${ }^{1}$ Cardiovascular and Metabolism Disease Area, Novartis Institutes for BioMedical Research, \\ Cambridge, Massachusetts 02139, USA \\ 2Division of Endocrinology, Metabolism, and Lipid Research, Department of Medicine, \\ Washington University School of Medicine, St Louis, Missouri 63110, USA \\ ${ }^{3}$ Islet Biology and Regenerative Medicine, Joslin Diabetes Center, Boston, Massachusetts 02215, \\ USA
}

\begin{abstract}
Endoplasmic reticulum (ER) stress causes pancreatic $\beta$-cell dysfunction and contributes to $\beta$-cell loss and the progression of type 2 diabetes ${ }^{1,2}$. Wolfram syndrome 1 (WFS1) has been shown to be an important regulator of the ER stress signalling pathway ${ }^{3}$; however, its role in $\beta$-cell function remains unclear. Here we provide evidence that WFS1 is essential for glucose- and glucagon-like peptide 1 (GLP-1)-stimulated cyclic AMP production and regulation of insulin biosynthesis and secretion. Stimulation with glucose causes WFS1 translocation from the ER to the plasma membrane, where it forms a complex with adenylyl cyclase 8 (AC8), an essential cAMPgenerating enzyme in the $\beta$-cell that integrates glucose and GLP-1 signalling ${ }^{4}$. ER stress and mutant WFS1 inhibit complex formation and activation of AC8, reducing cAMP synthesis and insulin secretion. These findings reveal that an ER-stress-related protein has a distinct role outside the ER regulating both insulin biosynthesis and secretion. The reduction of WFS1 protein on the plasma membrane during ER stress is a contributing factor for $\beta$-cell dysfunction and progression of type 2 diabetes.
\end{abstract}

Recent studies reveal that ER stress probably contributes to pancreatic $\beta$-cell dysfunction and may be the tipping point for the $\beta$-cell loss seen in patients with type 2 diabetes ${ }^{1,2,5}$. WFS1 is an ER membrane glycoprotein highly expressed in the insulin-producing $\beta$-cells of islets, and regulates the ER stress signalling pathway $3,6,7$. Both humans and mice deficient in WFS1 have $\beta$-cell loss, possibly as a result of a dysregulated ER stress response ${ }^{8,9}$. Therefore, WFS1 is important for ER homeostasis in the $\beta$-cell; however, its role in $\beta$-cell function is unknown.

To determine whether WFS1 plays a role in $\beta$-cell stimulus-secretion coupling, we overexpressed WFS1 in primary rat islets. A fivefold overexpression of WFS1 upregulated

\footnotetext{
(C) 2012 Macmillan Publishers Limited. All rights reserved.

${ }^{4}$ Correspondence should be addressed to S.G.F. (sonya.fonseca@ novartis.com).

Note: Supplementary Information is available in the online version of the paper

AUTHOR CONTRIBUTIONS
}

S.F., J.G. and M.B. wrote the manuscript and together with F.U. and G.C.W. conceived the experiments. S.F. carried out most of the experimental work. M.B. and J.G. directed the research programme.

COMPETING FINANCIAL INTERESTS

The authors declare no competing financial interests. 
insulin gene expression $(105 \pm 10 \%, P<0.05, n=3)$ (Fig. 1a), which was associated with enhanced biosynthesis of the insulin precursor, proinsulin $(190 \pm 8 \%, P<0.01, n=3$; Fig. 1b), and total cellular insulin content $(74 \pm 4 \%, P<0.01, n=3$; Fig. 1c). Islets with WFS1 overexpression showed a $39 \pm 6 \%(P<0.05, n=3)$ increase in glucose-stimulated insulin secretion (GSIS), compared with control islets, when normalized to insulin content (Fig. 1d). We can rule out the possibility that the increase in insulin biosynthesis and secretion by WFS1 overexpression is due to reduced ER stress levels, because the expression of key ER stress genes immunoglobulin heavy chain-binding protein $(B i P), \mathrm{C} / \mathrm{EBP}$ homologous protein $(C H O P)$ and spliced $\mathrm{X}$-box binding protein 1 ( $s X B P 1)$ did not change in islets overexpressing WFS1 following glucose stimulation (Fig. 1e-g). Enhanced stimulation of insulin secretion by glucose was confirmed following overexpression of WFS1 in human islets (Fig. 1h).

Over 100 mutations in WFS1 have been identified in patients with Wolfram syndrome, a disease characterized by juvenile diabetes and optical atrophy ${ }^{10}$. We overexpressed three WFS1 mutants in an INS-1 832/13 $\beta$-cell line in which endogenous WFS1 protein was suppressed using inducible short hairpin RNA (shRNA) against Wfs 1 . Insulin gene expression in these cells was reduced by $43-45 \%(P<0.01, n=3$; Fig. 1i). Figure $1 \mathrm{j}$ shows that GSIS in the mutant cells was suppressed by $45-52 \%(P<0.01, n=3)$. A similar suppression of insulin gene expression and GSIS was observed in INS1 832/13 cells with $>90 \%$ knockdown of WFS1 in the absence of mutant WFS1 expression (Fig. 1i,j). Insulin gene expression and GSIS were similar to control in cells co-expressing endogenous and mutant WFS1 (Fig. 1i,j), and was restored in knockdown cells with re-expression of wildtype WFS1 (data not shown). Consistent with our data in cell lines expressing mutant WFS1 and a previous report ${ }^{11}$, we found reduced insulin gene expression $(55 \pm 5 \%, P<0.05, n=$ 3; Fig. 1k), insulin content ( $47 \pm 4 \%, P<0.01, n=3$; Fig. 11$)$ and GSIS ( $40 \pm 9 \%, P<0.05$, $n=3$; Fig. $1 \mathrm{~m})$ in islets isolated from WFS1-deficient $\left(W f_{S} 1^{-/-}\right)$mice when compared with islets obtained from wild-type littermates. The defect in GSIS in $W f s 1^{-1-}$ islets can be rescued with WFS1 re-expression (Fig. 1n). We next investigated whether WFS1 could modulate insulin processing by measuring the secreted proinsulin to insulin ratio. In rat islets overexpressing WFS1 and in $W f_{S} 1^{-1-}$ islets, this ratio is comparable to control islets (Supplementary Fig. S1a,b). Together, these data demonstrate that WFS1 is required for both insulin biosynthesis and GSIS.

Next we investigated the possibility that WFS1 modulates insulin production and release through cAMP, a second messenger regulating both insulin biosynthesis and secretion ${ }^{12-14}$. Figure 2a shows that overexpression of WFS1 in rat islets increases glucose-induced cellular cAMP synthesis by $90 \pm 11 \%(P<0.01, n=3)$. Consistent with the idea that enhancement of insulin production and release by cAMP is mediated in part by protein kinase A (PKA) activation $^{15}$, we found that the PKA inhibitor H-89 suppressed insulin gene expression (Fig. 2b) and GSIS in WFS1-overexpressing islets (Fig. 2c). Glucose stimulation of INS-1 832/13 cells expressing three WFS1 mutants did not enhance cAMP production and was reduced by $78 \pm 13 \%$ ( $P<0.01, n=3$; Fig. 2 d). Similar data were observed in INS-1 832/13 with $>90 \%$ knockdown of WFS1 (Fig. 2d). cAMP responsiveness to glucose stimulation was unaffected in cells expressing both endogenous and mutant WFS1 (Fig. 2d) and was restored in mutant cell lines and $W f_{S} 1^{-l-}$ islets with re-expression of wild-type WFS1 (data not shown). Cells with WFS1 knockdown also had a small but significant defect in the amount (Fig. 2e) and rate (Fig. 2f) of glucose-induced $\mathrm{Ca}^{2+}$ increase $\left(\left[\mathrm{Ca}^{2+}\right]_{\mathrm{i}}\right)$. This defect can be explained, in part, by the suppression of key $\beta$-cell genes that comprise the glucose-sensing machinery (Supplementary Fig. S2). These data demonstrate that the main effect of WFS1 on insulin release is distal of $\left[\mathrm{Ca}^{2+}\right]_{i}$. 
WFS1 is an important regulator of the ER stress pathway ${ }^{7}$. Therefore, we explored the effect of ER stress on WFS1-mediated and glucose-stimulated cAMP production and insulin secretion. Although the defect in cAMP production and insulin release is apparent in 5week-old $W f_{S} 1^{-l-}$ islets and progresses with age (Fig. 3a,b), ER stress, defined by increases in the following ER stress markers: BiP, CHOP, activating transcription factor 4 (ATF4) and sXBP1 (Fig. 3c-f), is not noteworthy in these 5-week-old islets. We then assessed whether mitigation of ER stress in older $W_{f S} 1^{-1-}$ islets with the chemical chaperone 4-phenylbuytric acid (4-PBA) could rescue both the cAMP and GSIS defect (Fig. 3g-1). 4-PBA significantly reduced ER stress in $W_{f S} 1^{-1-}$ islets (Fig. 3i-1); however, this did not translate into a restoration of $\beta$-cell function (Fig. 3g,h). This suggests that it is the absence of WFS1 expression and not general ER stress that causes the $\beta$-cell functional defects in $W f_{S} 1^{-1-}$ islets. We also found that treatment of control islets with the ER stress inducer thapsigargin (Tg) caused a reduction in cAMP production and GSIS (Fig. 3m,n). Overexpression of WFS1, however, enhanced both cAMP synthesis $(95 \pm 6 \%, P<0.01, n=3$; Fig. $3 \mathrm{~m})$ and GSIS ( $36 \pm 4 \%, P<0.05, n=3$; Fig. $3 n$ ) in the presence of Tg when compared with untreated control cells. These data suggest that WFS1 is critical for $\beta$-cell function and overexpression of WFS1 can restore cAMP signalling and insulin release during ER stress insult.

GLP-1 and glucose-dependent insulinotropic hormone (GIP) are important gut hormones that stimulate insulin release through enhancement of cAMP signalling ${ }^{16}$. As expected, GLP-1 and GIP increased cAMP levels (Fig. 4a) and insulin secretion in wild-type mouse islets (Fig. 4b). Interestingly, glucose along with GLP-1 and GIP lacked the ability to increase cAMP and insulin release in $W f s 1^{-1-}$ islets (Fig. 4a,b). These islets also had an impaired response to forskolin (Fig. 4a,b), a diterpene shown to enhance cAMP synthesis ${ }^{17}$. The lack of an insulin secretory response in the $W f S 1^{-1-}$ islets is due to the lack of cAMP production and not a defect in the insulin secretory machinery, as the membrane-permeable cAMP analogue, dibutyl cAMP (DBcAMP), stimulated insulin release in $\mathrm{WfS}_{S} \mathrm{I}^{-/-}$islets similar to that observed in islets isolated from wild-type littermates (Fig. 4b). This defect also cannot be attributed to upregulation of cAMP hydrolysis by phosphodiesterases (PDEs), as treatment of $W f_{S} 1^{-1-}$ islets with the PDE inhibitor, 3-isobutyl-1-1 methylxanthine (IBMX) did not enhance cAMP accumulation or insulin secretion (Fig. 4a,b). GLP-1 and GIP receptor expression was unchanged in $\mathrm{WfS}_{\mathrm{f}} \mathrm{I}^{-/-}$islets (data not shown). Furthermore, the sulphonylurea glyburide and potassium chloride $(\mathrm{KCl})$ produced robust and similar increases in insulin secretion in wild-type and $W f_{S} 1^{-1-}$ islets (Fig. $4 \mathrm{~b}$ ). WfS $1^{-1-}$ islets also responded similarly to wild-type islets when treated with the protein kinase $\mathrm{C}$ activator, phorbol 12-myristate 13-acetate (data not shown). These data demonstrate that WFS1 regulates glucose- and gut-hormone-induced cAMP production and insulin release in the $\beta$ cell, but does not affect the ability of cAMP-independent pathways to stimulate insulin secretion.

cAMP production is regulated through the activation of multiple adenylyl cyclase isoforms ${ }^{15}$. We confirmed that WFS1 enhancement of cAMP is secondary to upregulation of total adenylyl cyclase activity (Fig. 4c). Glucose and GLP-1 have been shown to specifically activate the $\mathrm{Ca}^{2+} /$ calmodulin-dependent $\mathrm{AC} 8$ isoform ${ }^{4,18,19}$, suggesting that WFS1 regulation of cAMP may be through regulation of AC8. We further investigated whether WFS1-mediated cAMP production is due to modulation of AC8 expression or activity. AC8 gene and protein expression were unchanged by WFS1 overexpression in rat islets and INS-1 832/13 cells, as well as in $W f_{S} 1^{-1-}$ islets (Supplementary Fig. S3a-e). To probe for a possible interaction between the WFS1 and AC8 proteins, endogenous AC8 was immunoprecipitated from INS-1 832/13 lysates with or without overexpression of WFS1 (Fig. 4d,e). Western blot analyses provided evidence of complex formation between WFS1 and AC8 (Fig. 4d, lanes 9-12), as well as between WFS1 and calmodulin (Supplementary 
Fig. S4a, lanes 5 and 6). Stimulatory glucose increased endogenous WFS1 complex formation with AC8 $(85 \pm 9 \%, P<0.01, n=3$; Fig. 4 e) $)$ and with calmodulin $(320 \pm 28 \%, P$ $<0.01, n=3$; Supplementary Fig. S4b). Overexpression of WFS1 enhanced complex formation with AC8 $(111 \pm 10 \%, P<0.01, n=3)$ and between AC8 and calmodulin $(101 \pm$ $13 \%, P<0.05, n=3$; Fig. 4e). No complex formation was seen between WFS1 and the other $\mathrm{Ca}^{2+}$ /calmodulin-dependent adenylyl cyclase isoform, AC1 (Fig. 4f,g), nor with AC6 (Supplementary Fig. S5a,b), confirming the specificity of the WFS1-AC8-calmodulin complex. As expected, WFS1 did not complex with other cAMP pathway proteins such as protein phosphatase 2 (PP2A and Supplementary Fig. S5c), PKA (Supplementary Fig. S5d) and exchange protein directly activated by cAMP 2 (Epac2; Supplementary Fig. S5e), and important PDEs of the $\beta$-cell, PDE3b and PDE7 (ref. 20 and Supplementary Fig. S5f,g). Moreover, in INS-1 832/13 cells expressing WFS1 mutations, the glucose-dependent WFS1-AC8-calmodulin complex formation was not evident (Fig. 4h, lanes 5 and 6) and, more importantly, the AC8-calmodulin complex was also not detected (Fig. 4h,i).

We further explored the formation of the WFS1-AC8-calmodulin complex during ER stress. Consistent with our data showing impairment of cAMP signalling with ER stress (Fig. 3m), we found that Tg treatment prevented WFS1-AC8-calmodulin complex formation (Fig. 4j, lane 8). WFS1-AC8 complex formation in control cells was reduced (71 $\pm 15 \%, P<0.01, n=3$ ) and AC8-calmodulin complex formation was also reduced (48 \pm $9 \%, P<0.01, n=3$ ) with Tg treatment (Fig. 4k). WFS1-AC8 and AC8-calmodulin complex formation with $\mathrm{Tg}$ treatment remained significantly higher in cells overexpressing WFS1 than in control cells (Fig. 4k). Confirming previous studies ${ }^{18}$, knockdown of AC8 in INS-1 $832 / 13$ cells by $>60 \%$ suppressed GSIS by $48 \pm 8 \%(P<0.05, n=3$; Fig. 41$)$. This defect could not be rescued by WFS1 overexpression (Fig. 4l). In accordance, the enhancement of GSIS in rat islets by WFS1 overexpression was abolished by treatment with a general adenylyl cyclase inhibitor (data not shown). These data suggest that WFS1 is an essential component in activated AC8-calmodulin complex formation, a step required for $\beta$ cell cAMP synthesis, and this complex can be disrupted by ER stress causing $\beta$-cell dysfunction.

WFS1 was identified as an ER transmembrane protein 7 ; thus, complex formation with the plasma membrane protein AC8 needed further investigation. We assessed whether WFS1 could translocate out of the ER following glucose stimulation to form a complex with AC8 and calmodulin. WFS1 does not contain traditional ER retention sequences ${ }^{6}$; therefore, we investigated whether it could be held in the ER under steady-state conditions by an ERresident chaperone, similar to the way other ER membrane proteins are retained ${ }^{21}$. Previous studies indicate that WFS1 and the ER chaperone glucose-regulated protein 94 (GRP94) form a complex in neuronal cells ${ }^{22}$. Here, we show that WFS1 and GRP94 form a glucosedependent complex in $\beta$-cells. When GRP94 is immunoprecipitated from INS-1 832/13 cells, a strong interaction is seen under basal conditions (Fig. 5a, lane 6), which weakens with glucose stimulation (Fig. 5a, lane 7 and Fig. 5b), but reforms in the presence of $\mathrm{Tg}$ treatment (Fig. 5a, lane 8 and Fig. 5b). These results suggest that under basal conditions, GRP94 retains WFS1 in the ER and when stimulated with glucose, GRP94 releases WFS1 allowing WFS1 to escape the ER. In the presence of ER stress, the GRP94-WFS1 complex reforms, presumably to maintain WFS1 in the ER to fulfil its function in ameliorating ER stress; however, this leads to an overall reduction in $\beta$-cell function as seen in Fig. $3 \mathrm{~m}-\mathrm{n}$.

To determine whether WFS1 forms a complex with AC8 and calmodulin at the plasma membrane, we performed plasma membrane fractionation studies (Fig. 5c). To confirm enrichment of the plasma membrane, the fractionation samples were probed with anti- $\mathrm{Na}^{+} /$ $\mathrm{K}^{+}$ATPase (Fig. 5c). Both AC8 and calmodulin were present at the plasma membrane under basal and stimulated conditions (Fig. 5c, lanes 5 and 7), whereas GRP94 and another ER 
luminal protein, BiP, were excluded from these fractions (Fig. 5c, lanes 5-8). Under basal conditions, $20 \pm 6 \%(P<0.05, n=3)$ of total WFS1 was found at the plasma membrane, which increased to $46 \pm 3 \%(P<0.01, n=3)$ on stimulation with glucose but was reduced to levels similar to basal conditions with Tg treatment (Fig. 5d), suggesting the importance of ER localization of WFS1 during ER stress.

We further evaluated the translocation of WFS1 from the ER by immunocytochemistry (Fig. 5e). As expected, WFS1 co-localizes with the ER marker protein disulphide isomerase (PDI) in unstimulated cells (Fig. 5e, (1)); however, the WFS-PDI co-localization coefficient ratio is reduced ( $40 \pm 5 \%, P<0.01, n=3$ ) with glucose stimulation (Fig. 5e, (2) and Fig. 5f), which corresponds to an increase in the co-localization coefficient between WFS1 and the Golgi marker giantin (Fig. 5e, (4) and Fig. 5f). Consistent with a recent study ${ }^{23}$, WFS1 colocalizes with a marker of insulin granules, chromagranin A (ChrA; Fig. 5e, (5, 6)), which also increases $(90 \pm 11 \%, P<0.05, n=3)$ with glucose stimulation (Fig. 5f). In line with our plasma membrane fraction data, WFS1 co-localizes with the plasma membrane marker $\beta$ catenin (bCat) in both unstimulated and stimulated cells (Fig. 5e, $(7,8)$ ). Collectively, these findings suggest that glucose causes a translocation of WFS1 from the ER to the Golgi and stimulates the accumulation of WFS1 on the plasma membrane, where it forms a complex with AC8-calmodulin, and stimulates insulin biosynthesis and secretion.

Together, these data provide a more detailed understanding of insulin biosynthesis and secretion in the pancreatic $\beta$-cell, and provide insight into a mechanism by which $\beta$-cells balance ER stress with overall function. Our results demonstrate that WFS1 is essential for the active complex formation of AC8 and calmodulin, which is required for both cAMP synthesis and amplification of insulin expression and secretion, and that this process is perturbed by ER stress (Fig. 5g). ER stress traps WFS1 in the ER membrane, preventing AC8-CaM complex formation and activation of the cAMP signalling cascade. Although it is possible that ER stress may not be exclusively affecting WFS1 shuttling to the plasma membrane, we propose that its role in regulation of WFS1 translocation is a negative feedback loop to reduce ER workload during stress by preventing insulin biosynthesis. This is the first example of the requirement of an ER-resident protein for glucose and gut hormone signalling in the $\beta$-cell. Previous reports demonstrate a clear relationship between defects in cAMP signalling and diabetes ${ }^{24,25}$, as well as between ER stress and diabetes ${ }^{1,2}$. On the basis of our data, WFS1 is a key link between ER stress and $\beta$-cell function.

Although it is clear that WFS1 has dual roles in ER stress regulation and cAMP generation, it remains unclear whether these functions are entirely independent. We therefore postulate that in patients with type 2 diabetes, pathological ER stress contributes to $\beta$-cell dysfunction through a defect in the translocation of WFS1 to the plasma membrane.

\section{METHODS}

\section{Cell culture and plasmids}

For generation of $\beta$-cells with inducible overexpression of WFS1 or GFP, INS-1 832/13 cells were transduced with the tetracycline repressor, pTetR Tet-On (TO), and then transduced with a lentivirus expressing human WFS1-FLAG or GFP. For inducible overexpression, cells were cultured in $2 \mu \mathrm{M}$ doxycycline for $48 \mathrm{~h}$ before secretion assays and protein/RNA isolation. For generation of cells with inducible knockdown of WFS1, INS-1 832/13 pTetR TO cells were transduced with a lentivirus expressing shRNA against rat $W f_{s} 1$, and cultured in $2 \mu \mathrm{M}$ doxycycline for $48 \mathrm{~h}$ before protein/RNA isolation and secretion assays. For generation of stable mutant WFS1 cell lines, INS-1 832/13 pTetR TO shWFS1 cells were transfected with mutant WFS1 plasmids using Lipofectamine 2000 (Invitrogen) and cultured in $2 \mu \mathrm{M}$ doxycycline for $48 \mathrm{~h}$ to suppress endogenous WFS1 
expression before protein/RNA isolation and secretion assays. Wolfram syndrome disease mutant plasmids (P724L, ins483fs/ter544, G695V) were generated as previously described ${ }^{3}$.

\section{Primary islet isolation and transduction}

Male Sprague Dawley rats weighing 250-300 g (Charles River) were anaesthetized by intraperitoneal injection with a cocktail of ketamine, xylazine and acepromazine. Pancreatic islets were isolated as previously described ${ }^{26}$. Five- and ten-week-old pancreatic $\beta$-cellspecific Wfs1-knockout and Cre-positive control mouse islets were generated as previously described $^{9}$. All animal procedures were performed in accordance with animal welfare regulations under an approved institutional Animal Care and Use Committee protocol in the Novartis Institute for Biomedical Research and University of Massachusetts Medical School animal facilities, which are accredited by the Association for Assessment and Accreditation of Lab Animal Care. Human islets were obtained from Prodo Laboratories (www.prodolabs.com). Islets were plated on laminin-5 (Chemicon)-coated tissue culture dishes $18 \mathrm{~h}$ post-isolation, and transduced with $1.0 \times 10$ (ref. 9) viral particles per millilitre of lentivirus expressing human WFS1 or GFP. At $16 \mathrm{~h}$ post-transduction, the medium was changed and the islets were incubated for $24 \mathrm{~h}$ before performing secretion assays and collecting RNA/protein.

\section{Glucose-stimulated secretion assays}

Cell lines and primary rodent islets were pre-incubated with $5 \mathrm{mM}$ glucose overnight, and then stimulated with $2.5 \mathrm{mM}$ or $16.7 \mathrm{mM}$ glucose for $2 \mathrm{~h}$. Proinsulin secretion, insulin secretion and insulin content were measured by the Luminex assay, cellular cAMP was measured by ELISA according to the manufacturer's protocol (Cell Biolabs) and adenylate cyclase activity was measured using a cAMP HiRange membrane assay HTRF according to the manufacturer's protocol (Cisbio). Insulin secretion was normalized by DNA content using CyQUANT (Invitrogen) or insulin content as described above. DBcAMP, IBMX, KCl and 4-PBA were purchased from Sigma; GIP, GLP-1 and forskolin were purchased from American Peptide Company; glyburide and H-89 were purchased from Calbiochem.

\section{Proinsulin biosynthesis}

Proinsulin biosynthesis was analysed by proinsulin immunoprecipitation of $\left[{ }^{35} \mathrm{~S}\right]$ methionine-radiolabelled islet lysates as previously described ${ }^{27}$.

\section{Immunoblotting, immunocytochemistry and antibodies}

For immunoblotting, cell lysates were isolated, separated by SDS-PAGE and electroblotted as previously described ${ }^{7}$. The blots were imaged using an Odyssey infrared imaging system (LI-COR Biosciences). For immunocytochemistry, cells were fixed with 4\% PFA, probed overnight with primary antibodies and then probed for $1 \mathrm{~h}$ with secondary fluorophores. The following primary antibodies were used: 1:250 anti-WFS1 (\#sc-67180), 1:250 anti-adenylyl cyclase 8 (\#sc-20764), 1:250 anti-adenylyl cyclase 1 (\#sc-25743), 1:250 anti-PDE3b (\#sc-20793), 1:250 anti-PDE7 (\#sc-11136), 1:250 anti-Epac2 (\#sc-25633), 1:250 antichromagranin A (ChrA; \#sc-13090) and 1:250 anti-adenylyl cyclase 6 (\#sc-25500) from Santa Cruz Biotechnology; 1:2,000 anti-actin (\#MS-1295-P0) from Thermo Scientific (Fremont); 1:500 anti-calmodulin (CaM; \#05-173) from Millipore; 1:1,000 anti- $\beta$-catenin (bCat; \#9582), 1:1,000 anti-GRP94 (\#2104), 1:1,000 anti-BiP (\#3183), 1:1,000 anti-PP2A (\#9780) and 1:2,000 anti-GAPDH (\#2118) from Cell Signaling; 1:500 anti-insulin (\#I2018) from Sigma; 1:500 anti- $\mathrm{Na}^{+} / \mathrm{K}^{+}$ATPase (\#ALX-804-081) from Enzo; 1:500 anti-giantin (\#ab24586) and anti-PKA (\#ab75991) from Abcam; 1:500 anti-PDI (\#S34200) from Life Technologies. Secondary IRDye antibodies for immunoblotting were purchased from LICOR Biosciences and secondary fluorophores for immunocytochemistry were purchased 
from Life Technologies. Quantification of immunoblotted proteins was performed using ImageJ software (NIH) and quantification of immunostained proteins was performed using Zen software from Zeiss. A detailed description of calculating the co-localization coefficient has been previously described ${ }^{28}$.

\section{Immunoprecipitation}

Cells were lysed as previously described ${ }^{7}$. For immunoprecipitation of endogenous AC8, $\mathrm{CaM}$ or GRP94, $1 \mathrm{mg}$ whole-cell extract from each sample was incubated with $50 \mu \mathrm{l}$ Protein A/G agarose (Sigma) and $4 \mu \mathrm{g}$ anti-AC8, anti-CaM, anti-AC1, anti-AC6, anti-GRP94, antiPP2A, anti-PKA, anti-Epac2, anti-PDE3b or anti-PDE7 antibody overnight at $4{ }^{\circ} \mathrm{C}$ with rotation. After incubation, the agarose was washed four times with TNE buffer $(50 \mathrm{mM}$ Tris-HCl, $150 \mathrm{mM} \mathrm{NaCl}, 1 \mathrm{mM}$ EDTA and 1\% NP-40) followed by a final wash in $1 \times$ PBS (pH 7.4). The immunoprecipitation products were resolved by SDS-PAGE and then immunoblotted. As a control, the lysates were subject to immunoprecipitation as described above using rabbit or mouse IgG.

\section{Real-time polymerase chain reaction}

Total RNA was isolated from cells using the RNeasy Mini Kit and reverse transcribed using $1 \mu \mathrm{g}$ of total RNA from cells with oligo-dT primer. For thermal cycling, a 7900HT Fast Real-time PCR system (Applied Biosystems) was used at $95^{\circ} \mathrm{C}$ for $10 \mathrm{~min}$, then 40 cycles at $95{ }^{\circ} \mathrm{C}$ for $10 \mathrm{~s}$, and at $55^{\circ} \mathrm{C}$ for $30 \mathrm{~s}$. The relative amount for each transcript was calculated by a standard curve of cycle thresholds for serial dilutions of the complementary DNA sample and normalized to $\beta$-actin expression. The PCR was performed in triplicate for each sample; all experiments were repeated three times. The following primers were used: rat actin, $5^{\prime}$-GCAAATGCTTCTAGGCGGAC- $3^{\prime}$ and $5^{\prime}$ AAGAAAGGGTGTAAAACGCAGC- $3^{\prime}$; rat insulin $1,5^{\prime}$ GTCCTCTGGGAGCCCAAG- $3^{\prime}$ and $5^{\prime}$-ACAGAGCCTCCACCAGG- $3^{\prime}$; rat insulin 2, $5^{\prime}$ ATCCTCTGGGAGCCCCGC-3' and $5^{\prime}$-AGAGAGCTTCCACCAAG- $3^{\prime}$; rat BiP, $5^{\prime}$ TGGGTACATTTGATCTGACTGGA- $3^{\prime}$ and $5^{\prime}$-CTCAAAGGTGACTTCAATCTGGG-3'; rat Chop, $5^{\prime}$-AGAGTGGTCAGTGCGCAGC- $3^{\prime}$ and $5^{\prime}-$ CTCATTCTCCTGCTCCTTCTCC- $3^{\prime}$; rat spliced Xbp-1, $5^{\prime}$ CTGAGTCCGAATCAGGTGCAG-3' ${ }^{\prime}$ and $5^{\prime}$-ATCCATGGGAAGATGTTCTGG-3'; mouse actin, $5^{\prime}$-GCAAGTGCTTCTAGGCGGAC-3' and 5'AAGAAAGGGTGTAAAACGCAGC-3'; for mouse BiP, $5^{\prime}$ TTCAGCCAATTATCAGCAAACTCT- $3^{\prime}$ and $5^{\prime}$ TTTTCTGATGTATCCTCTTCACCAGT- $3^{\prime}$; mouse Chop, $5^{\prime}$ CCACCACACCTGAAAGCAGAA- $3^{\prime}$ and $5^{\prime}$-AGGTGAAAGGCAGGGACTCA- $3^{\prime}$; mouse spliced Xbp-1, 5' ${ }^{\prime}$ CTGAGTCCGAATCAGGTGCAG- $3^{\prime}$ and $5^{\prime}$ -

GTCCATGGGAAGATGTTCTGG-3' ${ }^{\prime}$; mouse insulin $1,5^{\prime}$ GAAGTGGAGGACCCACAAGTG- ${ }^{\prime}$ and $5^{\prime}$-CTGAAGGTCCCCGGGGCT-3 ${ }^{\prime}$; mouse

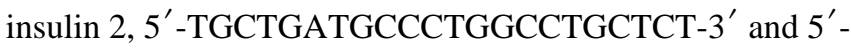
CTGGTCCCACATATGCACATGCA- $3^{\prime}$; mouse Glut2, $5^{\prime}$ GTGTGAGGATGAGCTGCCTAAA-3' and 5' -TTCGAGTTAAGAGGGAGCGC-3'; mouse Atf4, 5' -GAAACCTCATGGGTTCTCCA-3' and 5' AGCTCATCTGGCATGGTTTC-3'; mouse Gck, 5'-GAAAAGATCATTGGCGGAAA-3' and $5^{\prime}$-CCCAGAGTGCTCAGGATGTT- $3^{\prime}$; mouse Sur1, $5^{\prime}$ ATTGCTGCCGTCCTCATTAC- $3^{\prime}$ and $5^{\prime}$-CTGCACTGGACAGGAACTCA-3 ${ }^{\prime}$; mouse Pc $1 / 3,5^{\prime}$-TTGGCTGAAAGGGAAAGAGA- $3^{\prime}$ and $5^{\prime}$ GCTTCATGTGCTCTGGTTGA-3'; mouse Kir6.1, 5' CACAAGAACATCCGAGAGCA-3 ${ }^{\prime}$ and $5^{\prime}$-TCTTCTCCATGGTGCCTTTC-3'. 


\section{Plasma membrane fractionation}

Plasma membrane protein was isolated using a Qproteome plasma membrane kit (Qiagen).

\section{Intracellular $\mathrm{Ca}^{2+}$ measurements}

Intracellular $\mathrm{Ca}^{2+}$ was measured using the FLIPR Calcium 4 assay kit (Molecular Devices).

\section{Statistical analysis of data}

Significance was calculated by two-tailed paired Student's $t$-test. A $P$ value of less than 0.05 was considered statistically significant. All values are shown as means \pm s.d.

\section{Supplementary Material}

Refer to Web version on PubMed Central for supplementary material.

\section{Acknowledgments}

We thank M. Hara, Y. Adachi, Y. Murakami, L. Leahy, K. Sargent, B. O'Sullivan-Murphy, J. Hollister-Lock, J. Brown, K. Lipson, D. Ahern-Ridlon and X. Wang, for expert technical support; and C. Fonseca, S. Bonner-Weir and G. Waters for data discussions and comments on the manuscript. This work was supported by grants from the NIH (DK067493, DK016746, P60 DK020579, RR024992 and UL1 TR000448) and JDRF (11-2011-40) to F.U.

\section{References}

1. Laybutt DR, et al. Endoplasmic reticulum stress contributes to $\beta$ cell apoptosis in type 2 diabetes. Diabetologia. 2007; 50:752-763. [PubMed: 17268797]

2. Huang CJ, et al. Induction of endoplasmic reticulum stress-induced $\beta$-cell apoptosis and accumulation of polyubiquitinated proteins by human islet amyloid polypeptide. Am. J. Physiol. Endocrinol. Metab. 2007; 293:E1656-E1662. [PubMed: 17911343]

3. Fonseca SG, et al. WFS1 is a novel component of the unfolded protein response and maintains homeostasis of the endoplasmic reticulum in pancreatic $\beta$-cells. J. Biol. Chem. 2005; 280:3960939615. [PubMed: 16195229]

4. Delmeire D, et al. Type VIII adenylyl cyclase in rat $\beta$ cells: coincidence signal detector/generator for glucose and GLP-1. Diabetologia. 2003; 46:1383-1393. [PubMed: 13680124]

5. Marchetti $P$, et al. The endoplasmic reticulum in pancreatic $\beta$ cells of type 2 diabetes patients. Diabetologia. 2007; 50:2486-2494. [PubMed: 17906960]

6. Takeda K, et al. WFS1 (Wolfram syndrome 1) gene product: predominant subcellular localization to endoplasmic reticulum in cultured cells and neuronal expression in rat brain. Hum. Mol. Genet. 2001; 10:477-484. [PubMed: 11181571]

7. Fonseca SG, et al. Wolfram syndrome 1 gene negatively regulates ER stress signalling in rodent and human cells. J. Clin. Invest. 2010; 120:744-755. [PubMed: 20160352]

8. Karasik A, et al. Genetically programmed selective islet $\beta$-cell loss in diabetic subjects with Wolfram's syndrome. Diabetes Care. 1989; 12:135-138. [PubMed: 2649325]

9. Riggs AC, et al. Mice conditionally lacking the Wolfram gene in pancreatic islet $\beta$ cells exhibit diabetes as a result of enhanced endoplasmic reticulum stress and apoptosis. Diabetologia. 2005; 48:2313-2321. [PubMed: 16215705]

10. Hardy C, et al. Clinical and molecular genetic analysis of 19 Wolfram syndrome kindreds demonstrating a wide spectrum of mutations in WFS1. Am. J. Hum. Genet. 1999; 65:1279-1290. [PubMed: 10521293]

11. Ishihara $\mathrm{H}$, et al. Disruption of the WFS1 gene in mice causes progressive $\beta$-cell loss and impaired stimulus-secretion coupling in insulin secretion. Hum. Mol. Genet. 2004; 13:1159-1170. [PubMed: 15056606] 
12. Yajima $\mathrm{H}$, et al. cAMP enhances insulin secretion by an action on the ATP-sensitive $\mathrm{K}^{+}$channelindependent pathway of glucose signalling in rat pancreatic islets. Diabetes. 1999; 48:1006-1012. [PubMed: 10331404]

13. Henquin JC. Triggering and amplifying pathways of regulation of insulin secretion by glucose. Diabetes. 2000; 49:1751-1760. [PubMed: 11078440]

14. Idevall-Hagren O, Barg S, Gylfe E, Tengholm A. cAMP mediators of pulsatile insulin secretion from glucose-stimulated single $\beta$-cells. J. Biol. Chem. 2010; 285:23007-23018. [PubMed: 20498366]

15. Seino S, Shibasaki T. PKA-dependent and PKA-independent pathways for cAMP-regulated exocytosis. Physiol. Rev. 2005; 85:1303-1342. [PubMed: 16183914]

16. Holz, GGt; Kuhtreiber, WM.; Habener, JF. Pancreatic $\beta$-cells are rendered glucose-competent by the insulinotropic hormone glucagon-like peptide-1 (7-37). Nature. 1993; 361:362-365. [PubMed: 8381211]

17. Pinto C, et al. Activation and inhibition of adenylyl cyclase isoforms by forskolin analogs. J. Pharmacol. Exp. Ther. 2008; 325:27-36. [PubMed: 18184830]

18. Roger B, et al. Adenylyl cyclase 8 is central to glucagon-like peptide 1 signalling and effects of chronically elevated glucose in rat and human pancreatic $\beta$ cells. Diabetologia. 2011; 54:390-402. [PubMed: 21046358]

19. Holz GG, Heart E, Leech CA. Synchronizing $\mathrm{Ca}^{2+}$ and cAMP oscillations in pancreatic $\beta$-cells: a role for glucose metabolism and GLP-1 receptors? Focus on 'regulation of cAMP dynamics by $\mathrm{Ca}^{2+}$ and $\mathrm{G}$ protein-coupled receptors in the pancreatic $\beta$-cell: a computational approach'. Am. J. Physiol. Cell. Physiol. 2008; 294:C4-C6. [PubMed: 17989206]

20. Walz HA, et al. Beta-cell PDE3B regulates $\mathrm{Ca}^{2+}$-stimulated exocytosis of insulin. Cell Signal. 2007; 19:1505-1513. [PubMed: 17368848]

21. Shen J, Prywes R. Dependence of site-2 protease cleavage of ATF6 on prior site-1 protease digestion is determined by the size of the luminal domain of ATF6. J. Biol. Chem. 2004; 279:43046-43051. [PubMed: 15299016]

22. Kakiuchi C, et al. Valproate, a mood stabilizer, induces WFS1 expression and modulates its interaction with ER stress protein GRP94. PLoS One. 2009; 4:e4134. [PubMed: 19125190]

23. Hatanaka M, et al. Wolfram syndrome 1 gene (WFS1) product localizes to secretory granules and determines granule acidification in pancreatic $\beta$-cells. Hum. Mol. Genet. 2011; 20:1274-1284. [PubMed: 21199859]

24. Dachicourt N, Serradas P, Giroix MH, Gangnerau MN, Portha B. Decreased glucose-induced cAMP and insulin release in islets of diabetic rats: reversal by IBMX, glucagon, GIP. Am. J. Physiol. 1996; 271:E725-E732. [PubMed: 8897861]

25. Dolz M, et al. cAMP-secretion coupling is impaired in diabetic GK/Par rat $\beta$-cells: a defect counteracted by GLP-1. Am. J. Physiol. Endocrinol. Metab. 2011; 301:E797-E806. [PubMed: 21750265]

26. Montana E, Bonner-Weir S, Weir GC. Beta cell mass and growth after syngeneic islet cell transplantation in normal and streptozocin diabetic C57BL/6 mice. J. Clin. Invest. 1993; 91:780787. [PubMed: 8450059]

27. Alarcon C, Wicksteed B, Prentki M, Corkey BE, Rhodes CJ. Succinate is a preferential metabolic stimulus-coupling signal for glucose-induced proinsulin biosynthesis translation. Diabetes. 2002; 51:2496-2504. [PubMed: 12145163]

28. Zinchuk V, Zinchuk O. Quantitative colocalization analysis of confocal fluorescence microscopy images. Curr. Protoc. Cell Biol. 2008 
a

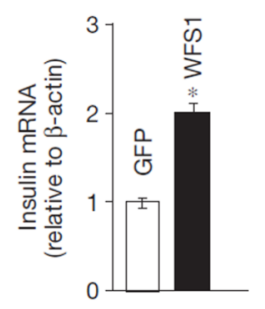

g

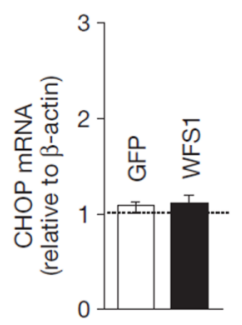

b
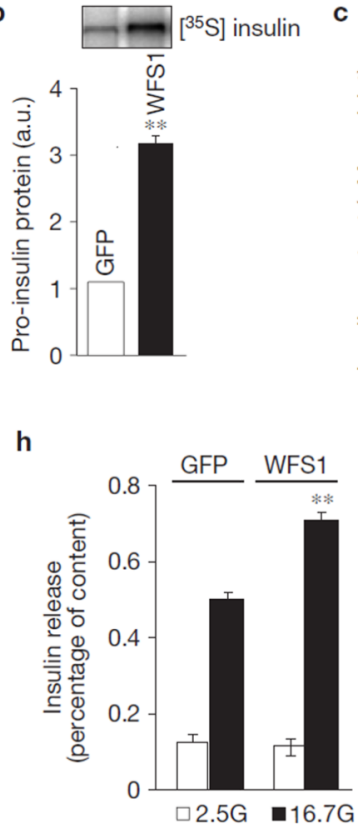

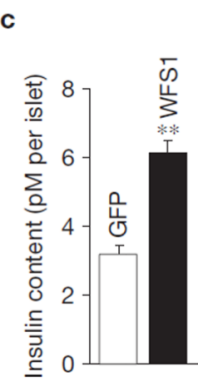

d

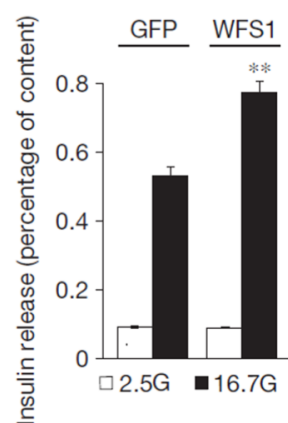

i e

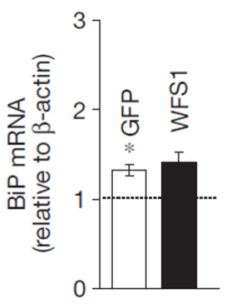

f

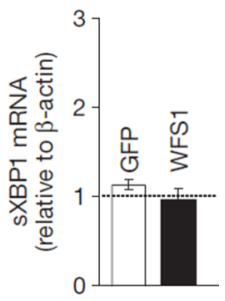

k

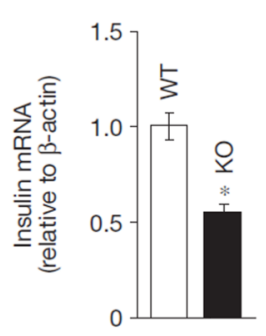

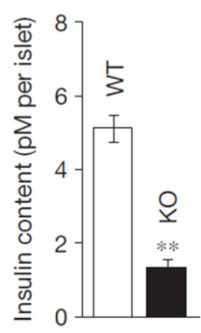
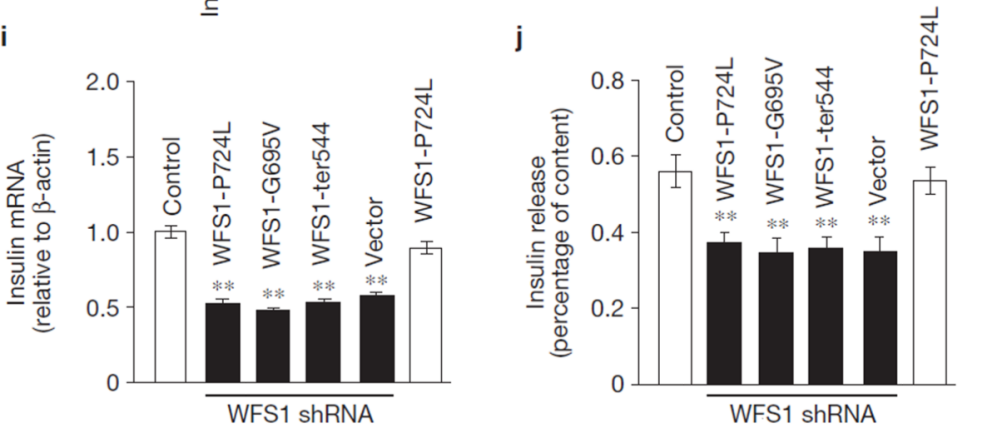

Figure 1.

m

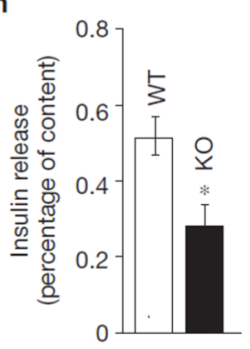

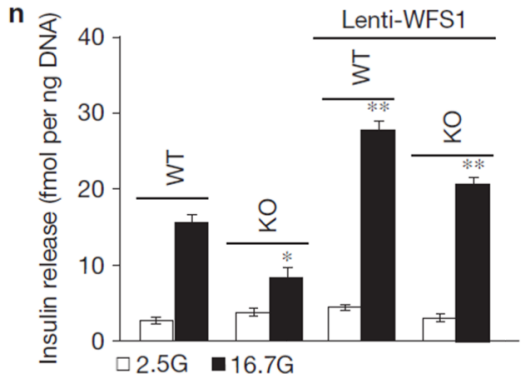

WFS1 is required for insulin production, storage and secretion in $\beta$-cells. (a) Relative expression of Ins 1 and Ins 2 measured by quantitative PCR (Ins 2 represented in figure; similar for Ins 1; $n=3$ ) in rat islets transduced with either GFP or WFS1 lentivirus and incubated with $16.7 \mathrm{mM}$ glucose $(16.7 \mathrm{G})$ for $2 \mathrm{~h}$. (b) Pro-insulin biosynthesis measured by immunoblot analysis of immunoprecipitated ${ }^{35} \mathrm{~S}$-labelled insulin in rat islets prepared as in a. ${ }^{35} \mathrm{~S}$-labelled insulin was quantified with Image $\mathrm{J}$ and is expressed in arbitrary units (a.u.; $n$ $=3)$. c, Insulin content measured in rat islets prepared as in $\mathbf{a}(n=3)$. (d) Insulin release measured in rat islets prepared as in a and normalized to insulin content $(n=3)$. ${ }^{* *} P<0.01$ when compared with GFP (16.7G). (e-g) Relative expression of BiP (e), sXBP1 (f) and CHOP (g) measured by quantitative PCR and normalized to $2.5 \mathrm{G}$ (dashed line) in rat islets prepared as in $\mathbf{d}(n=3)$. (h) Insulin release measured in human islets prepared as in $\mathbf{a}$ ( $n=$ $3)$. ${ }^{* *} P<0.01$ when compared with GFP (16.7G). (i) Relative expression levels of Ins1 and Ins 2 measured by quantitative PCR (Ins 2 represented in figure; similar for Ins $1 ; n=3$ ) in INS-1 832/13 pTetR cells (Control), expressing the WFS1 disease mutant P724L or shRNA against $W f_{S} 1$ and expressing the following WFS1 disease mutants: WFS1-P724L, WFS1 ${ }^{\mathrm{G} 695 \mathrm{~V}}$ or ins483/ter544 (WFS1-ter544). ${ }^{* *} P<0.01$ when compared with control. (j) Insulin release measured in the same cell lines as $\mathbf{i}$, treated with $16.7 \mathrm{G}$ and normalized to insulin content $(n=3)$. (k) Relative expression of Ins 1 and Ins 2 measured by quantitative PCR (Ins2 represented in figure; similar for Ins 1 ) in $W f_{s} 1^{+/+}(\mathrm{WT})$ and $W f_{S} 1^{-/-}(\mathrm{KO})$ mouse islets $(n=3)$. (l) Insulin content measured in WT and KO islets treated with $16.7 \mathrm{G}$ 
for $2 \mathrm{~h}(n=3)$. (m) Insulin release measured in WT and $\mathrm{KO}$ islets treated as in $\mathbf{I}$ and normalized to insulin content $(n=3)$. (n) Insulin release measured in WT and KO islets with or without lenti-WFS 1 and treated with $2.5 \mathrm{G}$ or $16.7 \mathrm{G}$ for $2 \mathrm{~h}$. Insulin levels were normalized to total DNA content $(n=3)$. All data are means \pm s.d. ${ }^{*} P<0.05,{ }^{* *} P<0.01$. 
a

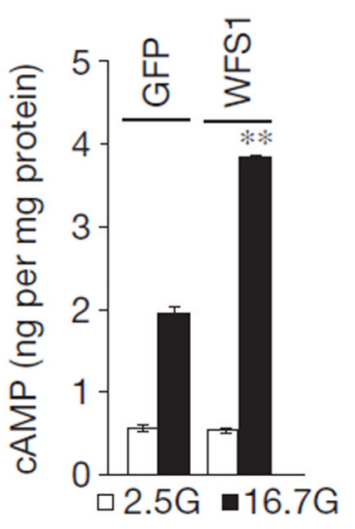

b

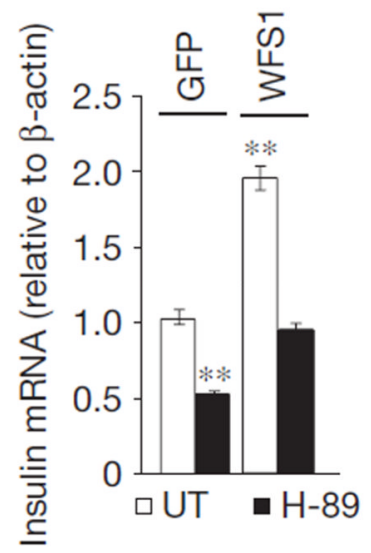

C

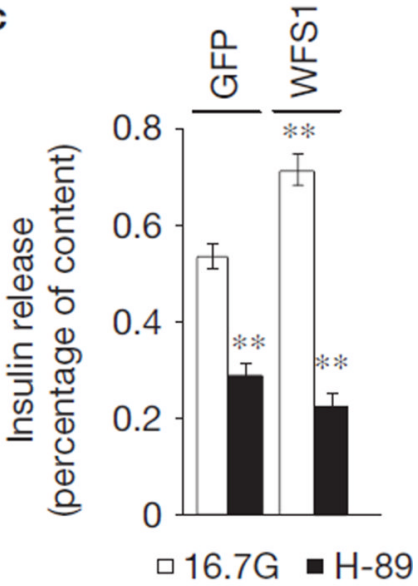

d

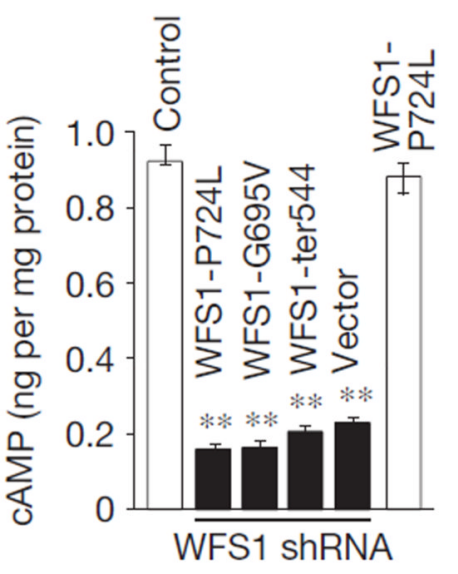

f

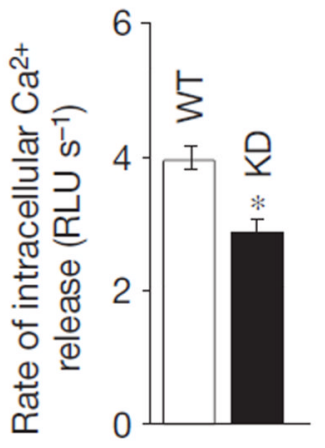

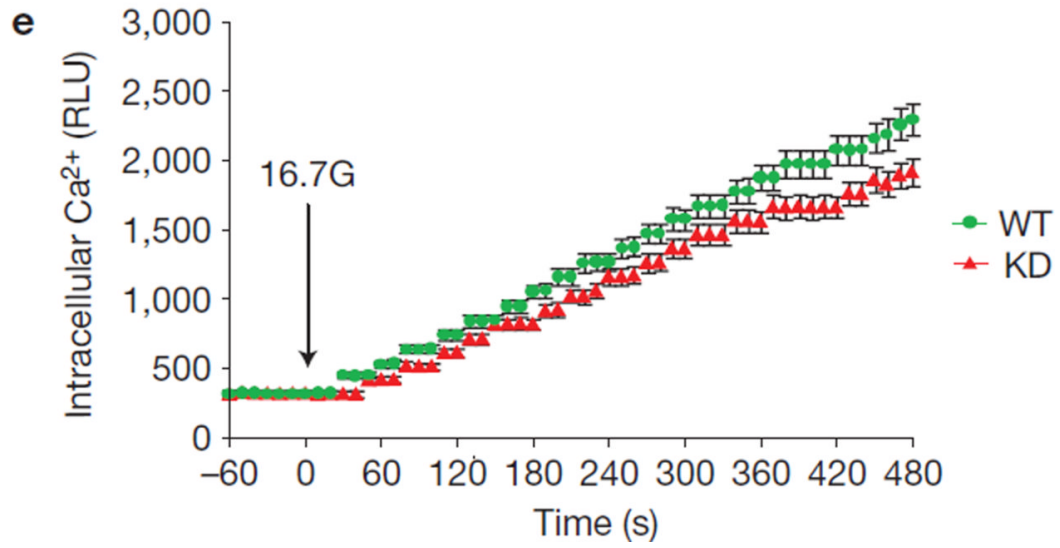

Figure 2.

WFS1 modulates cAMP production. (a) Total cellular cAMP content was measured in lysates from rat islets transduced with GFP or WFS1 lentivirus, and treated for $2 \mathrm{~h}$ with 2.5 $\mathrm{mM}$ glucose $(2.5 \mathrm{G})$ or $16.7 \mathrm{mM}$ glucose $(16.7 \mathrm{G})$. Cellular cAMP levels were normalized to total protein levels $(n=3)$. ${ }^{* *} P<0.01$ when compared with GFP $(16.7 \mathrm{G})$. (b) Total mRNA was prepared from islets generated the same as in a, treated with $16.7 \mathrm{G}$ or $16.7 \mathrm{G}$ with pretreatment of $10 \mu \mathrm{M} \mathrm{H}-89$ for $9 \mathrm{~h}$. Relative expression levels of both rodent insulin gene isoforms, Ins 1 and Ins2, were measured by quantitative PCR (Ins 2 represented in figure; similar expression levels found for Ins $1 ; n=3) .{ }^{* *} P<0.01$ when compared with GFP (UT). 
(c) Insulin release was measured in islets generated the same as in a, treated for $2 \mathrm{~h}$ with $16.7 \mathrm{G}$ or $16.7 \mathrm{G}$ with $10 \mu \mathrm{M} \mathrm{H}-89$. Insulin levels were normalized to total cellular insulin content $(n=3)$. ${ }^{* *} P<0.01$ when compared with GFP $(16.7 \mathrm{G})$. (d) Total cellular cAMP content was measured in lysates from INS-1 832/13 pTetR cells (Control), expressing the WFS1 disease mutant P724L or inducibly expressing shRNA against Wfs 1 and stably expressing the following WFS1 disease mutants: P724L, G695V or ins483/ter544 (ter544), and treated with $2.5 \mathrm{G}$ or $16.7 \mathrm{G}$ for $2 \mathrm{~h}$. Cellular cAMP levels were normalized to total protein levels and basal secretion subtracted from $16.7 \mathrm{G}(n=3) .{ }^{* *} P<0.01$ when compared with control. (e) Intracellular calcium was measured in INS-1 832/13 pTetR cells with endogenous WFS1 expression (WT) or suppression of endogenous WFS1 with shRNA (KD) treated with $16.7 \mathrm{G}$. (f) Intracelluar calcium release rate after $16.7 \mathrm{G}$ stimulation was quantified in WT and KD cells using the following formula: $\left(t_{0}\right.$ RLU- $t_{480}$ RLU)/480 $=$ RLU $\mathrm{s}^{-1}(n=3)$. All data are means \pm s.d. ${ }^{*} P<0.05,{ }^{* *} P<0.01$. 


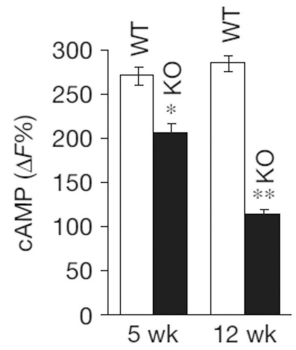

f

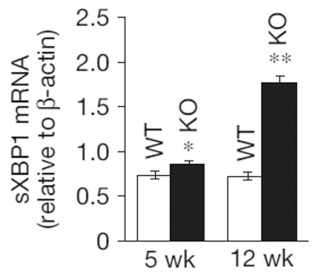

b

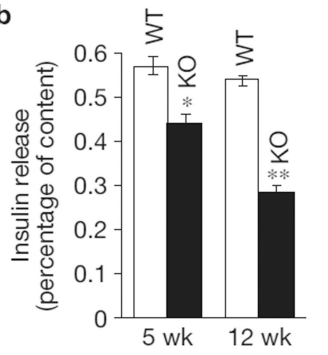

g

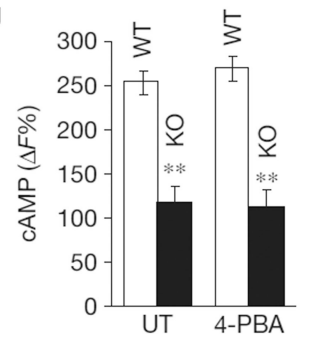

C

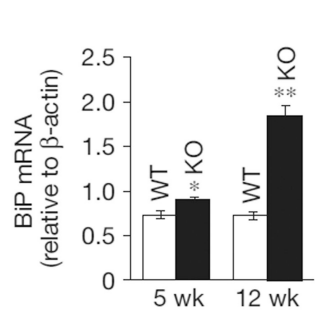

h

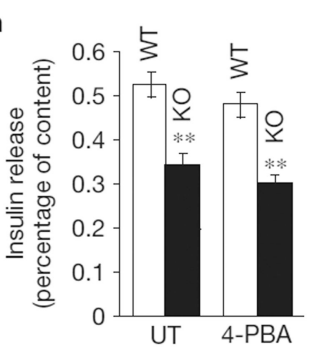

d

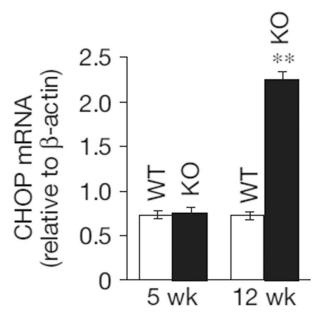

i

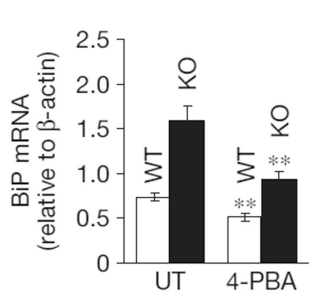

e k

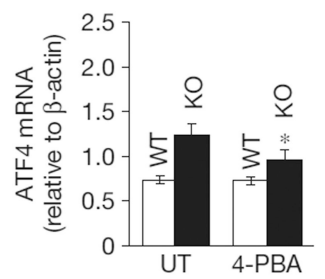

I

Figure 3 .

ER stress leads to cAMP defects in $\beta$-cells. (a) cAMP activity was measured using a cAMP HTRF assay in mouse islets from 5-week-old (5 wk) and 12-week-old (12 wk) Wf $f^{+/+}$ (WT) and $W f_{s} 1^{-1-}(\mathrm{KO})$ animals treated for $2 \mathrm{~h}$ with $16.7 \mathrm{mM}$ glucose $(16.7 \mathrm{G})$. (b) Insulin release was measured in 5-wk and 12-wk WT and KO islets treated as in a. Insulin levels were normalized to total insulin content $(n=3)$. (c-f) Total mRNA was prepared from 5-wk and 12-wk WT and KO islets. Relative expression levels of BiP (c), CHOP (d), ATF4 (e) and SXBP1 (f) were measured by quantitative PCR $(n=3)$. (g) cAMP activity was measured using a cAMP HTRF assay in islets from 12-wk WT and KO animals untreated (UT) or treated for $18 \mathrm{~h}$ with $2.5 \mathrm{mM}$ (determined to be the highest non-cytotoxic concentration in islets) of 4-PBA and then stimulated for $2 \mathrm{~h}$ with $16.7 \mathrm{G}(n=3)$. (h) Insulin release was measured in the same islets as in $\mathbf{g}$. Insulin levels were normalized to total insulin content ( $n$ =3). (i-l) Total mRNA was prepared from the same islets as in $\mathbf{g}$. Relative expression levels of the ER stress markers BiP (i), CHOP (j), ATF4 (k) and sXBP1 (l) were measured by quantitative PCR $(n=3)$. (m) Total cellular cAMP content was measured in lysates from rat islets transduced with GFP or WFS1 lentivirus, and treated for $2 \mathrm{~h}$ with $2.5 \mathrm{G}$ or $16.7 \mathrm{G}$ with or without $1 \mu \mathrm{M}$ Tg. Cellular cAMP levels were normalized to total protein levels $(n=3)$. * $P$ $<0.05,{ }^{* *} P<0.01, \ddagger P<0.001$ when compared with GFP (16.7G). (n) Insulin release was measured in the same islets as in $\mathbf{m}$. Insulin was normalized to insulin content and $2.5 \mathrm{G}(n=$ 3). ${ }^{* *} P<0.01$ when compared with GFP (16.7G). All data are means \pm s.d. 


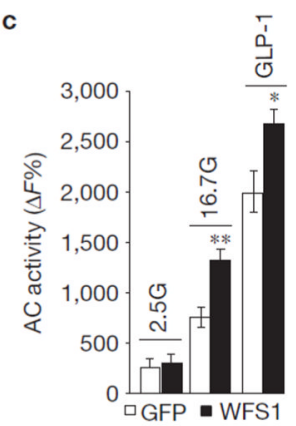

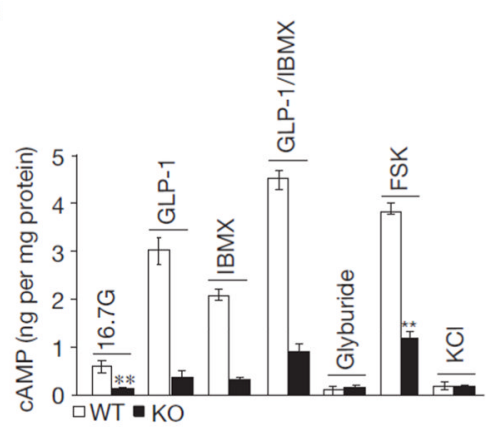

b

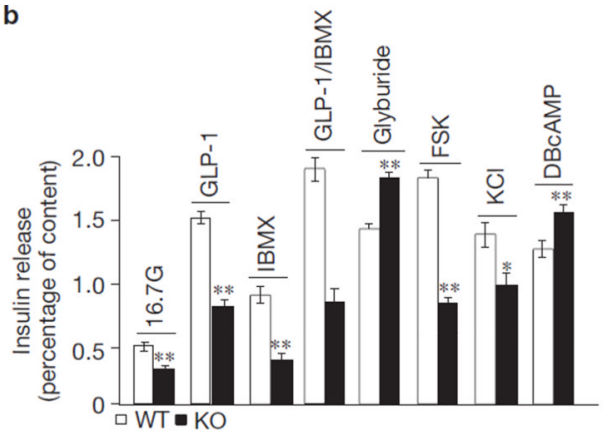

f

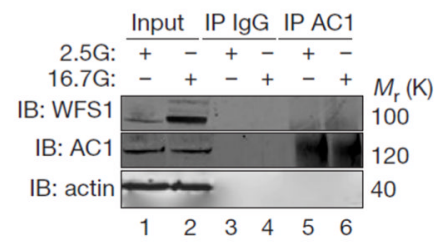

d
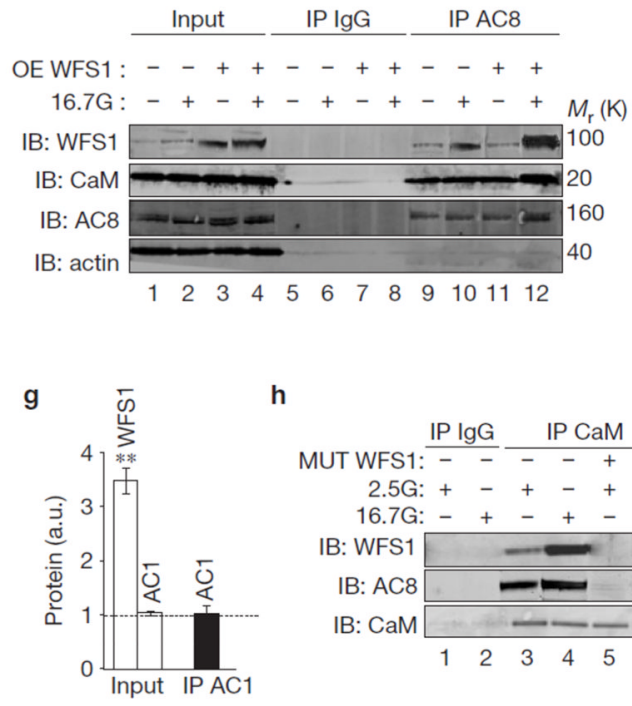

h

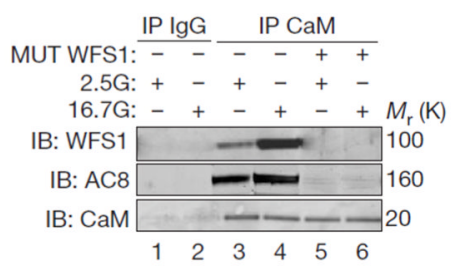

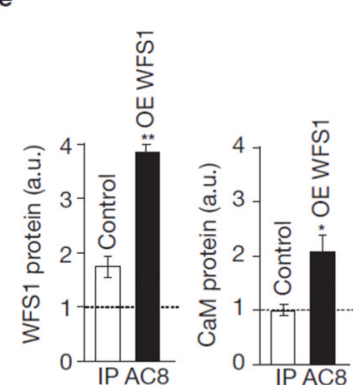

k

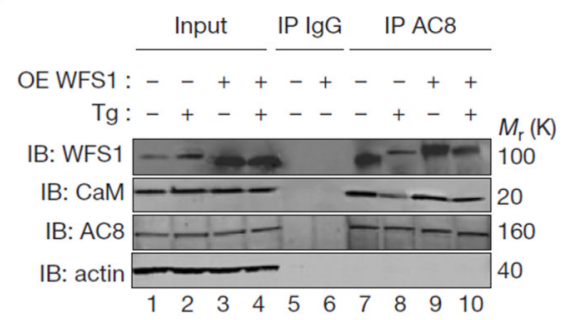

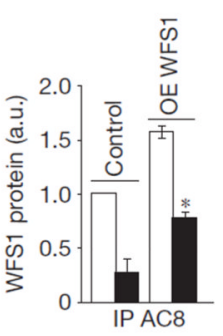

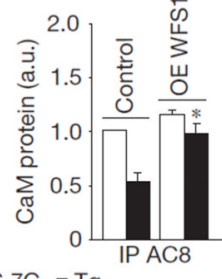

$\square 16.7 \mathrm{G} \cdot \mathrm{Tg}$

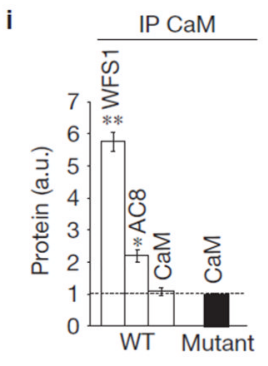

Figure 4.

WFS1 forms an active complex with AC8. (a) cAMP measured in $W f_{S} 1^{+/+}(\mathrm{WT})$ and $W f s 1^{-l-}(\mathrm{KO})$ islets treated with $2.5 \mathrm{mM}$ glucose $(2.5 \mathrm{G}), 16.7 \mathrm{mM}$ glucose $(16.7 \mathrm{G})$ or 16.7G with: $100 \mathrm{nM}$ GLP-1, $0.5 \mathrm{mM}$ IBMX, GLP-1 + IBMX, $100 \mu \mathrm{M}$ glyburide, $10 \mu \mathrm{M}$ forskolin (FSK) and $30 \mathrm{mM} \mathrm{KCl}$. cAMP was normalized to total protein $(n=3) .{ }^{* *} P<0.01$, $\ddagger P<0.001$ when compared with WT. (b) Insulin release measured in a including $1 \mathrm{mM}$ DBcAMP and normalized to insulin content $(n=3) .{ }^{*} P<0.05,{ }^{* *} P<0.01, \ddagger P<0.001$ when compared with WT. (c) Total adenylyl cyclase (AC) activity measured in rat islets transduced with GFP or WFS1 lentivirus treated for $2 \mathrm{~h}$ with $2.5 \mathrm{G}$ or $16.7 \mathrm{G}(n=3)$. ${ }^{*} P<$ 
$0.05,{ }^{* *} P<0.01$ when compared with GFP (16.7G). (d) AC8 immunoprecipitated (IP) from INS-1 832/13 pTetR cells overexpressing WFS1, treated with $2.5 \mathrm{G}$ or $16.7 \mathrm{G}$ for $1 \mathrm{~h}$. Immunoprecipitates immunoblotted (IB) with anti-WFS1, anti-AC8, anti-calmodulin (CaM) and anti-actin. (e) Quantification of 16.7G IP proteins as fold increase from 2.5G (dotted line) expressed in arbitrary units (a.u.; $n=3$ ). ${ }^{*} P<0.05,{ }^{* *} P<0.01$ when compared with WT. (f) AC1 IP from INS-1 832/13 treated the same as in d. Immunoprecipitates IB with anti-WFS1, anti-AC1 and anti-actin antibodies $(n=3)$. (g) Quantification of proteins the same as in e. ${ }^{* *} P<.01$ when compared with 2.5G. (h) CaM IP from INS-1 832/13 pTetR cells expressing shRNA against $W f s 1$ (shWFS1) \pm expression of WFS1 mutant P724L (MUT) and treated as in d. Immunoprecipitates were IB the same as in d. (i) Quantification of $16.7 \mathrm{G}$ IP proteins the same as in $\mathbf{g}(n=3) .{ }^{*} P<0.05,{ }^{* *} P<0.01$ when compared with 2.5G. (j) AC8 IP from the same cells as in a and treated with $16.7 \mathrm{G} \pm 1 \mu \mathrm{M}$ Tg for $2 \mathrm{~h}$. Immunoprecipitates IB the same as in $\mathbf{d}$. (k) Quantification of IP proteins expressed in a.u. $(n=3) .{ }^{*} P<0.05$ when compared with control (Tg). (l) Insulin release in the same cells as in $\mathbf{d}$ transfected with scramble shRNA (Scr) or shRNA against $A c 8$ (shAC8), and treated with doxycycline to ectopically express WFS1 (Scr/WFS1 and shAC8/WFS1). Insulin normalized to insulin content $(n=3)$. ${ }^{*} P<0.05,{ }^{* *} P<0.01$ when compared with Scr $(16.7 \mathrm{G})$. All data are means \pm s.d. Uncropped images of blots are shown in Supplementary Fig. S6. 
a

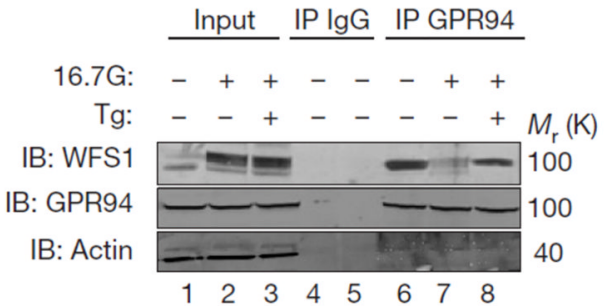

c

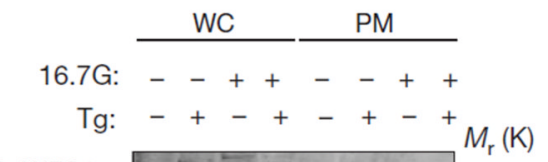

IB: WFS1 $-2=-100$

IB: AC8

IB: $\mathrm{CaM}$

IB: ATPase

IB: GRP94

IB: BiP

IB: GAPDH

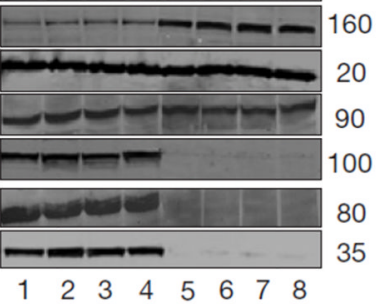

b

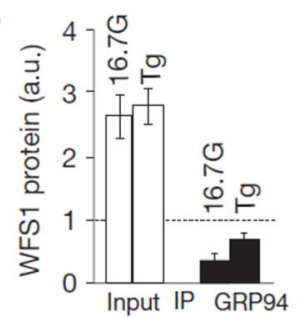

d

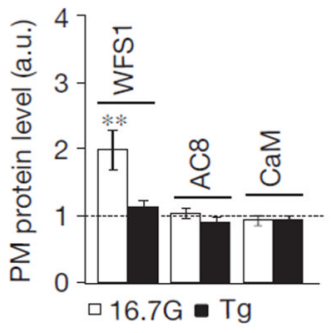

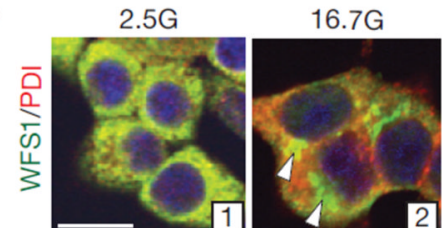
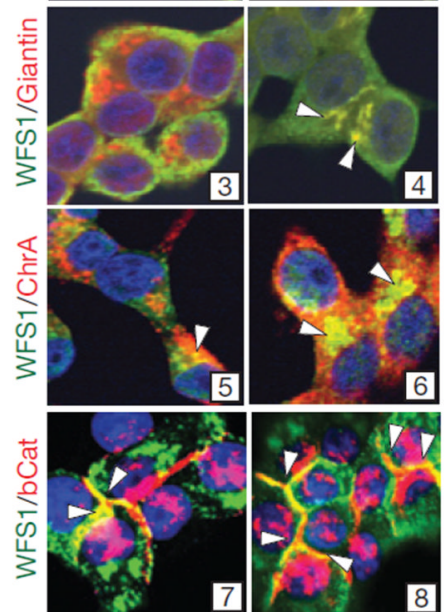

f

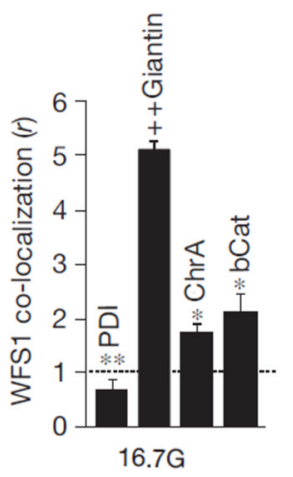

g

Normal

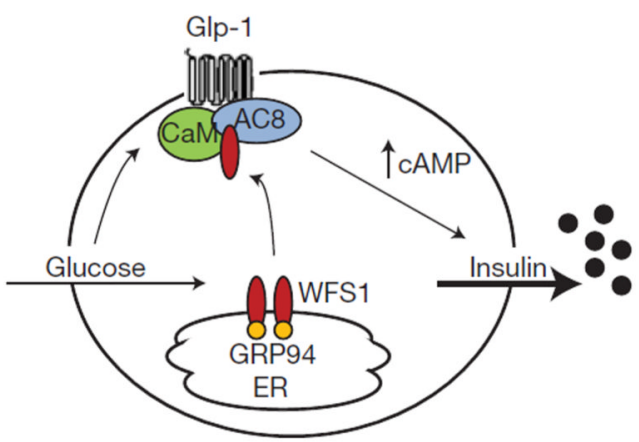

ER stress

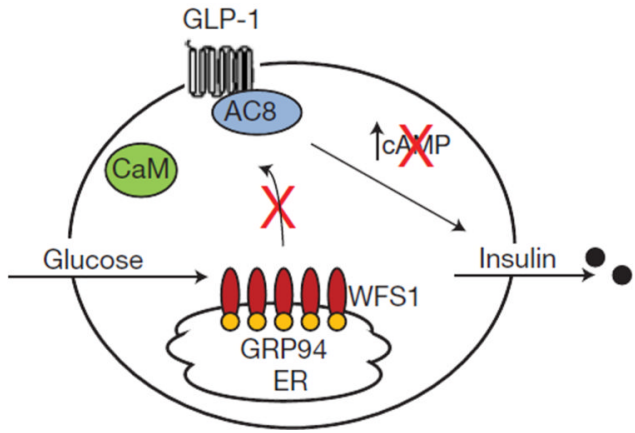

Figure 5.

WFS1 translocates from the ER to the plasma membrane in a glucose-dependent manner. (a) GRP94 was immunoprecipitated (IP) from cell lysates prepared from INS-1 832/13 cells treated for $2 \mathrm{~h}$ with either $2.5 \mathrm{mM}$ glucose $(2.5 \mathrm{G})$ or $16.7 \mathrm{mM}$ glucose $(16.7 \mathrm{G})$, with or without $1 \mu \mathrm{M}$ thapsigargin ( $\mathrm{Tg}$ ). Immunoprecipitates were immunoblotted (IB) with antiWFS1, anti-GRP94 and anti-actin antibodies $(n=3)$. (b) Quantification of input and IP proteins using ImageJ, as a fold increase from $2.5 \mathrm{G}$ (dotted line), and expressed in arbitrary units (a.u.; $n=3$ ). ${ }^{*} P<0.05$ when compared with IP GRP94 (16.7G). (c) Plasma membrane (PM) protein was isolated from INS-1 832/13 cells treated for $2 \mathrm{~h}$ with either $2.5 \mathrm{G}$ or $16.7 \mathrm{G}$, with or without $1 \mu \mathrm{M}$ Tg. Whole cell (WC) and PM lysates were IB with anti-WFS1, antiAC8, anti-CaM, anti-Na ${ }^{+} / \mathrm{K}^{+}$ATPase, anti-GRP94, anti-BiP and anti-GAPDH $(n=3)$. (d) Quantification of $16.7 \mathrm{G}$ and $\mathrm{Tg}$ PM proteins using Image $\mathrm{J}$, as a fold increase from $2.5 \mathrm{G}$ (dotted line; $n=3$ ). ${ }^{* *} P<0.01$ when compared with $2.5 \mathrm{G}$ proteins. (e) INS-1 832/13 cells treated with either $2.5 \mathrm{G}$ or $16.7 \mathrm{G}$ for $1 \mathrm{~h}$ were fixed and co-stained with anti-WFS 1 and the following: anti-PDI, anti-giantin, anti-chromagranin $\mathrm{A}(\mathrm{ChrA})$ and anti- $\beta$-catenin (bCat). 
Protein co-localization represented with scale bar, $10 \mu \mathrm{M}$ in image 1 (representative image of $n=10$ ). (f) Quantification of the WFS1 co-localization coefficient $(r)$ with co-stained proteins at $16.7 \mathrm{G}$ using Zeiss Zen software, as a fold increase from $2.5 \mathrm{G} .{ }^{*} P<0.05,{ }^{* *} P<$ $0.01, \ddagger P<0.001$ when compared with $2.5 \mathrm{G}$ proteins. All data are means \pm s.d. (g) Model of WFS1 modulation of cAMP. Under physiological conditions, glucose and GLP-1 stimulate WFS1 translocation from the ER to the plasma membrane, where WFS1 forms a complex with AC8 and CaM, stimulating cAMP synthesis and insulin secretion (left panel). Under ER stress, WFS1 is trapped in the ER, preventing complex formation between AC8 and $\mathrm{CaM}$, inhibiting cAMP synthesis and insulin secretion (right panel). Uncropped images of blots are shown in Supplementary Fig. S6. 